\title{
The Effects of Communicative Grammar Teaching on Students' Achievement of Grammatical Knowledge and Oral Production
}

\author{
Pham Vu Phi Ho ${ }^{1} \&$ Nguyen The Binh ${ }^{2}$ \\ ${ }^{1}$ HCMC Open University, Ho Chi Minh City, Vietnam \\ ${ }^{2}$ Le Hong Phong Junior High School, Ninh Thuan province, Vietnam \\ Correspondence: Pham Vu Phi Ho, HCMC Open University, Ho Chi Minh City, Vietnam. E-mail: \\ phamvuphiho@gmail.com
}

Received: March 12, 2014 Accepted: April 14, 2014 Online Published: May 14, 2014

doi:10.5539/elt.v7n6p74 URL: http://dx.doi.org/10.5539/elt.v7n6p74

\begin{abstract}
So far the students of Le Hong Phong Junior High School have been taught grammar with GTM (Grammar-Translation Method), which just prepares learners for conventional grammar-paper tests. Despite their considerable knowledge of grammar, the students fail to use the language they have learnt to communicate in real-life situations. The purpose of this study was to investigate whether the communicative grammar teaching method was effective in terms of students' grammatical knowledge and oral communication, and their attitudes towards this teaching method. The results of the study highlight the treatment on both grammatical knowledge and oral communication as well as positive attitudes from the students. These lead to two major conclusions that the communicative grammar teaching indeed helped the students improve their grammar competence and use it effectively in communication, at least in oral production. Besides, this implementation appealed the students' interest in grammar lessons.
\end{abstract}

Keywords: communicative grammar teaching, grammatical knowledge, oral production

\section{Background of the Study}

In the history of EFL teaching methods, various trends in grammar teaching have been applied to enhance learners' competence in a foreign language, typically Grammar-Translation Method (GTM), Direct Method (DM), Audio-lingual Method (ALM), Communicative Language Teaching (CLT), etc. Amongst these, CLT is one of the newest known methods; it is the most favorable in the current trend of language teaching. Generally, there are a lot of evidences showing that grammar should be taught in communicative ways that is commonly called CLT (Singh, 2011). Unlike the former methods, CLT is learner-centered, emphasizes communication and real-life situations. It views that learners will learn best if they participate in meaningful communication (ibid.). In brief, CLT itself has its own advantages, and it really does benefit learners in a variety of ways.

In this paper, the term "communicative grammar teaching" is used to refer to teaching grammar communicatively. According to "Grammar Practice: Mechanical and Communicative (n.d.)", this method of grammar teaching is based on the Communicative Language Teaching (CLT) to the teaching of second/ foreign languages. In the light of this method, language structures must not be taught in isolation but integrated to the four skills of language. A structure is practiced both orally and in written form. Grammar patterns must not only be learnt at the utterance level but also at the discourse level; the main objective focuses on the development of communicative grammatical competence, which is understood as the ability to use and understand a structure in a variety of situations spontaneously.

\section{Statement of the Problem}

With reference to the current trend of language teaching, CLT is supposed to primarily aim at developing learner's communicative competence. Therefore, the design of most textbooks developed by the MOET (Ministry of Education and Training) in Vietnam is somehow based on CLT. However, after many years of studying English at school with these textbooks, Vietnamese students cannot apply their linguistic ability to real-life situations. This reality originates from the fact that most teachers apply the traditional method namely GTM in training grammar, in which grammar rules are taught deductively (G. Nguyen \& H. Nguyen, 2004) and thus students keep learning grammar reluctantly in order to deal with conventional paper-tests (Khuong-Cam, 
2010). There are several possible explanations for this preference. First, teachers always feel more comfortable and confident when using GTM to teach grammar since this method of teaching is quite familiar to them (G. Nguyen \& H. Nguyen, 2004). Second, the school facilities cannot meet the demand of CLT application. Particularly, large-size classes are not ideal environment for a communicative lesson; and schools are deprived of equipment (e.g. audiovisual teaching aids) (ibid.). Last but not least, according to Khuong-Cam, this problem of English grammar teaching derives from such constraints as grammar-based examinations and textbook-based syllabi rather than those mentioned by G. Nguyen and H. Nguyen.

Relating this common reality to Le Hong Phong Junior High School, in Ninh Thuan province, Vietnam, the grammar teaching application has been in the same way. This truth is proved by the researcher's seventeen-year experience in teaching English at this school, through his hundreds of class observations and daily personal communications with practitioners and students (personal communication, 2012). To teachers, they all feel confident and comfortable in their current teaching, and thus totally satisfied with the way they have been applying to teach English grammar regardless of knowing that their students cannot use the language for communication. Sadly, most of them are quite vague about the CLT implementation (personal communication, 2012). Even a few scarce teachers who have an understanding of CLT express their negative view on it. They assert that applying CLT in grammar teaching faces a lot of difficulties due to certain constraints of school facilities; besides, it requires much endeavor from the teacher; they hence do not often implement it. For students, when being asked about the reality of grammar instruction they have been experienced, most of them state that what they learn from grammar classes is a series of grammatical structure provision followed by mechanical practice in the form of isolated sentences, which only serves conventional grammar-paper tests (personal communication, 2012). Consequently, though they have considerable knowledge of grammar, they cannot use English to communicate, even in simple situations like personal introduction.

Stimulated by the basis of the mentioned reality, a decision to conduct a study to help students get improved in English grammatical knowledge and communicative performance at least in the form of oral production is made. That is to say, the current study is conducted with two primary aims: (1) to investigate the effects of communicative grammar teaching on students' achievement of grammatical knowledge and oral production, and (2) to ascertain students' attitudes towards communicative grammar lessons. To obtain the above purposes, the study addresses the following research questions:

1) Does communicative grammar teaching affect students' achievement of grammatical knowledge and oral production?

2) What are the students' attitudes towards the communicative grammar teaching method?

\section{Methodology}

\subsection{Participants}

For this study, the two classes of $7^{9}$ and $7^{10}$ were selected to take part in the experiment as the control and the experimental group. This choice was based on the students' equivalence in English capability and certainly had to be under the school administrators' permission. Till the time right before the experiment, the two groups were somehow equivalent in several aspects: learning environment, learning conditions, learning chances, and learning aptitude. They were all at the age of twelve and had compulsorily learnt English for four years at school. They were supposed to be equal in English proficiency of elementary level. For more details of this aspect, a summary of participants' characteristics is displayed in Table 1.

Table 1. Summary of participants' characteristics at the beginning of the treatment

\begin{tabular}{lllllllll}
\hline \multirow{2}{*}{ Group } & \multirow{2}{*}{$\mathrm{N}$} & \multicolumn{2}{l}{ Gender } & \multicolumn{5}{c}{ Final scores on English subject at the end of grade 6 } \\
\cline { 3 - 9 } & & Male & Female & $<3.5$ & $3.5-4.9$ & $5.0-6.4$ & $6.5-7.9$ & $8.0-10$ \\
\hline \multirow{2}{*}{ Control } & 21 & 16 & 3 & 5 & 12 & 12 & 5 \\
& \multirow{2}{*}{37} & $56.8 \%$ & $43.2 \%$ & $8.1 \%$ & $13.5 \%$ & $32.5 \%$ & $32.5 \%$ & $13.5 \%$ \\
\multirow{2}{*}{ Experimental } & 37 & 19 & 18 & 4 & 4 & 10 & 13 & 6 \\
& & $51.4 \%$ & $48.6 \%$ & $10.8 \%$ & $10.8 \%$ & $27.0 \%$ & $35.2 \%$ & $16.2 \%$ \\
\hline
\end{tabular}


As can be seen in Table 3.1, both groups had the same total number of students: thirty-seven. The numbers of females between the two groups were not far different: sixteen in the control group and eighteen in the experimental group. The table indicates that there was no considerable disparity in English capability between the two groups. Assuming that the final scores on the English subject of grade 6 were valid, they might be seen as reference for establishing equivalence in English proficiency between the two groups at the beginning of the treatment. Accordingly, in this study, a pre-test would be in need to examine this equivalence.

\subsection{Design of the Study}

This research was designed to examine whether an intervention of CLT application in grammar teaching towards junior high school students' achievement of grammatical knowledge and oral production would be effective as well as their positive attitudes in relation to the grammar teaching method. For this purpose, the study followed a quasi-experimental study design in the form of pre-and post-tests with a control group. The design of the study is succinctly displayed in Figure 1.

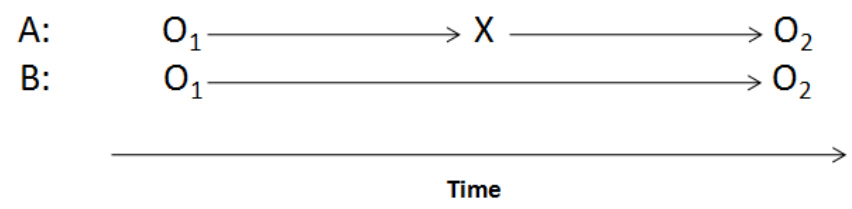

Figure 1. Design of the study

Note. $\mathrm{A}=$ experimental group, $\mathrm{B}=$ control group, $\mathrm{O}_{1}=$ pre-test, $\mathrm{O}_{2}=$ post-test, $\mathrm{X}=$ treatment

\subsection{Procedure}

The study lasted almost four months from the middle of August 2012 to the middle of December 2012, including the administrations of pre- and post-tests. The six major grammar points embraced in the curriculum of "Tiếng Anh 7" were in turn taken into the treatment as the normal curriculum. The full description of study procedure was chronologically illustrated as the three phases of pre-training, while- and post-training, and training process.

\subsubsection{Pre-Training Phase}

Before the treatment, all preparations were carefully made. First of all, six appropriate grammatical points embraced in the school syllabus were chosen to teach namely (1) comparatives of adjectives, (2) future simple tense, (3) exclamations, (4) superlatives of adjectives, (5) present progressive tense, and (6) adverbs of frequency. Then, in order to prepare for lesson planning, some popular course-books that were currently used as official language manuals in many language centers were taken into account so that various topics and communicative tasks were then adapted. Next, the six grammar lessons were planned in two different methods of GTM and CLT for two-group training practices afterwards. All the six grammar-lesson plans (both in GTM and CLT) were conventionally designed in the same model of P - P - P (presentation, practice, and production). However, the lesson plans for the treatment group were quite communication-oriented; tasks, techniques, and classroom activities were communicatively exploited in all three phases. Finally, the student questionnaire for the experimental group was concurrently designed. Also, the pre- and the post-tests were developed beforehand. Surely, all these study instruments were taken into tight pilot within a pilot group of ten students. Thanks to the pilot, the instruments were refined for appropriateness, their administrations and scoring were also well practiced prior to the current study.

\subsubsection{While- and Post-Training Phase}

In week 3 of the school-year (i.e. one week right before the training phase), the two pre-tests (i.e. a written test and an oral test) were officially administered to all participants of the two groups, which aimed at confirming the equivalence in English capacity of the two groups as well as providing data for the investigation on statistically significant differences afterwards. From week 4 to week 13, all the six treatments were respectively conducted on six separate days in accordance with the prescribed curriculum. Three days after the last treatment, the questionnaire was distributed to the treatment group to explore students' perceptions towards the treatment. It was completed on the spot within fifteen minutes and then returned to the researcher. Two weeks after the questionnaire distribution, both groups were assigned two post-tests (i.e. a written test and an oral test), which measured students' grammatical knowledge and orally communicative performance. 


\subsubsection{Training Process}

The training procedure summarized as in Figure 2 took place within ten weeks from the beginning of week 4 to the end of week 13. The three stages of presentation, practice, and production of each treatment were demonstrated in details as follows.

In the stage of presentation, the grammar points were inductively introduced to students through one of such contexts as a short reading text, a brief dialogue in which the target structure was embedded. Following the text was often one of such follow-up tasks as true/false, question-answer, or matching. Students were asked to deal with the text tasks individually or in pairs. Then, some prompting questions were posed by the teacher so as to get students involved in the target structures embedded in the text. Students were often asked to work in pairs to discuss the guiding questions and then derive the grammar rules with the teacher's facilitation. Once the students had shaped the new grammar rules, the teacher summed them up. He might also give some brief explanations if necessary. Before moving to the next stage of practice, the teacher checked students' understanding by using one of the useful tools like visual aids, objects, or conceptual questions.

In the practice stage, the students were usually asked to work in pairs, groups or individually to do both mechanical and meaningful practice. For mechanical practice, both kinds of oral and written practice were exploited with the aim of developing accuracy. Students had to do one or two oral practices such as repetitions and substitutions, and one written exercise of gap-fill or sentence building-up. With meaningful practice, they had to use the target structures to fulfill one or two of such fluency-based tasks as information gaps, role-plays, discussions, and often one parallel writing exercise. Definitely, apart from the form focus, this sub-phase was at the earlier concentration on the meaning and use of the grammar points. During this stage, the teacher took the role of a guide, a consultant, and a facilitator who assisted students with their communicative tasks. The teacher's feedback and error correction was given immediately in the hope to help students get accuracy.

In the production stage, the students were asked to produce the structures through some real-life situations, especially their own real life. In this stage, working in pairs or groups was often intensified; besides, the interaction between individuals and the whole class was effectively exploited. This fluency-oriented phase offered students wider opportunities to keep on participating in one or two of such communicative activities as role-plays, discussions, surveys, collaborative writing, etc. Dealing with these tasks, students were totally free to manipulate the target language communicating with their peers; thus, there was no sense in interrupting their working for any error correction then. The teacher was hence a facilitator, an organizer, or even a co-communicator to stimulate participation among students; all for the sake of boosting the students' communicating in the target language.

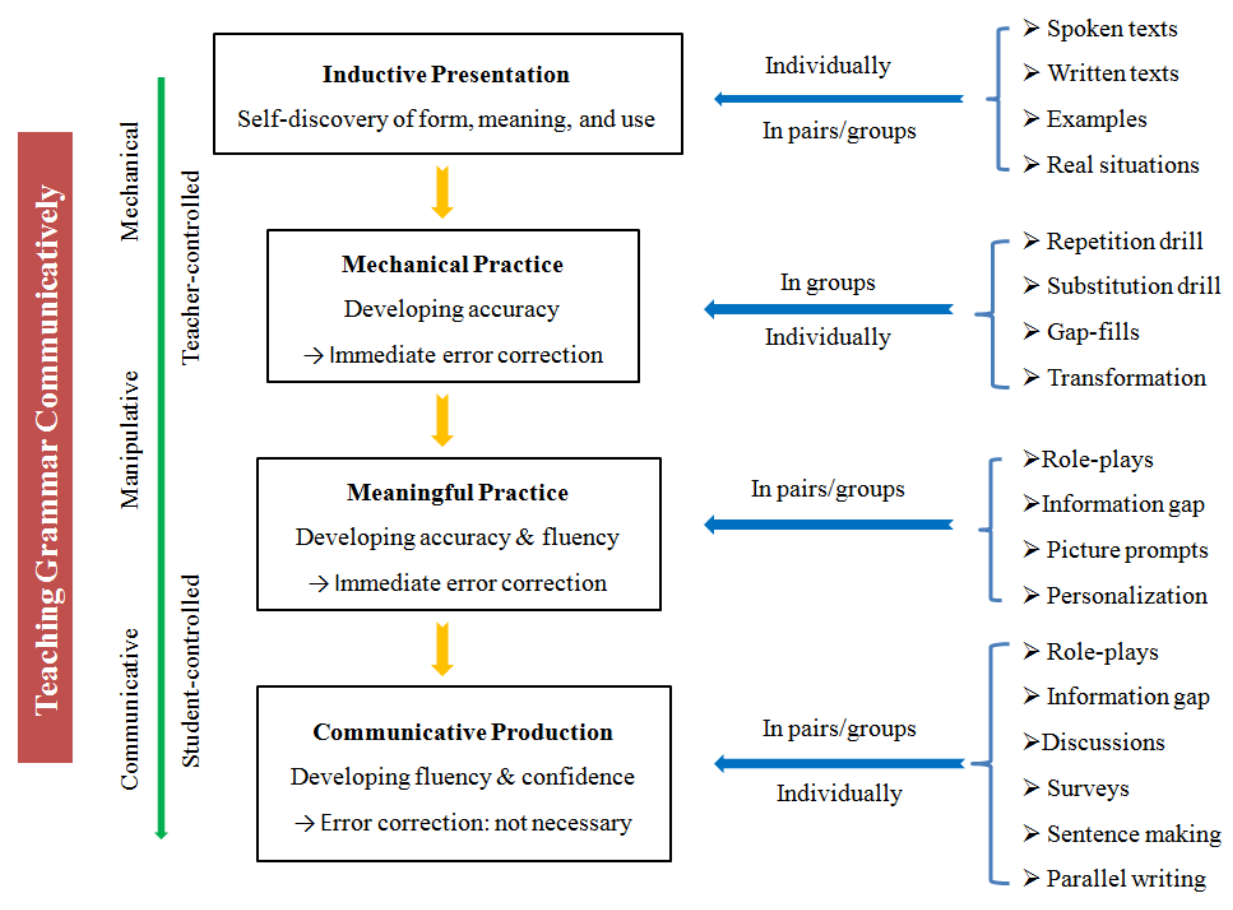

Figure 2. Conceptual framework for CLT application in grammar teaching 


\subsection{Data Collection}

\subsubsection{Student Questionnaire}

With reference to the current study, the questionnaire was designed including entirely close-ended questions that aimed to get specific aspects of the issue. All the close-ended questions of the questionnaire followed the five-point Likert's scale from 1 (strongly disagree) to 5 (strongly agree). As normal, the questionnaire consisted of two separate sections. The first section focused on seeking personal information about the respondents joining the treatment. Such information as ages, genders, length of English learning, and the final scores on English subject in the previous school-year were implied in this section. The second section-the main substance aimed at collecting data on the students' attitudes towards grammar lessons instructed with CLT. This section was developed with twenty-three items and four sub-items revolving students' evaluation of three main themes: lesson content (Questions 1-5), task design (Questions 6-10), and instruction effects on their learning interest (Questions 11-23). Dealing with the questionnaire, the participants were asked to complete it on the spot within fifteen minutes. Thirty-seven questionnaire papers (Vietnamese version) were administered to the participants three days after they had finished the last treatment. All efforts were made to translate it into the target language afterwards with the help of two experts in the field.

\subsubsection{Pre- and Post-Tests}

\subsubsection{Grammar-Paper Tests}

The grammar-paper tests were developed to collect data on the students' competence of the six instructed grammar points (i.e. future simple tense, exclamations, present progressive tense, comparative and superlative forms of adjectives, and adverbs of frequency). Both the pre- and the post-test were designed in the same matrix and with the same language content; however, the items embedded in the two tests were certainly quite different. Included in each test were twenty-five items which were apportioned in accordance with their prescriptive density of training. Particularly, the six grammar points of adverbs of frequency, future simple tense, present progressive tense, comparatives, superlatives, and exclamations respectively made up $20.0 \%, 17.5 \%, 17.5 \%$, $17.5 \%, 17.5 \%$, and $10.0 \%$ of each test.

With the current grammar-paper tests, the elicitation techniques suggested by Heaton (1989) namely multiple-choice items, completion items, transformation items, broken-sentence items, and sentence building-up items were used. Tackling these test tasks, the test takers were required to complete three sections: (A) Choose the best options that complete the sentences by cycling the letter A, B, C, or D-comprised ten isolated items; (B) Fill in the blanks of the sentences with the correct forms of the words in brackets - embraced eight isolated items; (C) Do as suggested in the forms of transformation, sentence-broken, and sentence building-up items-included seven separate items.

Accordingly, the total number of items of each test was 25; and time allotted for each test was 25 minutes. Scoring these types of selected responses and limited production responses needed a single criterion for grammatical correctness (Bachman \& Palmer, 1996); specifically, each correct answer of section A was marked 0.25 , each correct answer of section $\mathrm{B}$, or each complete sentence of section $\mathrm{C}$ was marked 0.5 point. However, for section $\mathrm{C}$, a three-point scale was used to mark the students' performance: 0.5 point for a complete sentence, 0.25 point for one grammatical error excluding the target one, and zero for incorrect target grammar. With respect to the two inter-raters, one male and one female, both had got Bachelor of Science and were over ten-year experienced in English teaching. They, of course, had been clearly explained the purpose, the significance of the test data beforehand, and well trained in scoring tests. They were also given the key answers and the scoring instruction for paper marking.

\subsubsection{Oral Production Tests}

For the present study, three suitable types of oral test were chosen: short talks, oral interviews, and picture descriptions. Basically, the pre- and the post-oral test were designed in the same format; except the photos for descriptions in the pre- and the post-test were different in terms of images but similar in terms of descriptions. Dealing with these task types, test takers were required to take part in dialogues and multi-interaction (Heaton, 1989). Particularly, the students were asked to: (1) with short talks, introduce the interlocutor their personal information; (2) for oral interviews, ask and respond to the partner's questions about habitual activities and future intentions; and (3) towards picture descriptions, report to the interlocutor ongoing activities and comparisons within the given photos.

Similar to the grammar-paper tests, the students' ability to use the instructed grammar points orally was assessed based on the scheme which was assigned in accordance with the prescriptive density of training of these target 
grammar points. Particularly, the five grammar points of adverbs of frequency, future simple tense, present progressive tense, and comparatives and superlatives respectively made up $15.0 \%, 15.0 \%, 20.0 \%$, and $30.0 \%$ of each test; and the personal introduction made up $20.0 \%$ of the test. Totally, each student had to speak at least thirteen sentences within the oral test. Time allotted for each pair was from 7 to 8 minutes. Regarding the oral tests, it took each group half a day to take part in one test. That means the oral tests were executed within four sessions totally.

Involved in the oral tests, two examiners were in need: the researcher took the role of an interlocutor; while his invited colleague who was just one of the paper-test raters took the responsibility of an assessor. Before the tests, all the test takers had been explained the format as well as the content of the oral tests; then they were called in pairs at a time; each pair was given from seven to eight-minute allotment. Students' performances were directly marked on the spot based on the developed rating rubric; simultaneously, they were recorded with an $\mathrm{MP}_{3}$ recorder for later remark. Naturally, before the implementation of the tests, the invited assessor had been carefully told about the purpose and the significance of the test data. She had also been clearly explained and guided how to mark students' performance based on the scoring rubrics.

\section{Findings and Discussion}

\subsection{Research Question 1: Does Communicative Grammar Teaching Affect the Students'Achievement of Grammatical Knowledge and Oral Production?}

To respond this research question, the descriptive statistics data that stemmed from the pre- and the post-tests were calculated and analyzed. In this study, the two measurements of mean (M) and standard deviation (S.D.) were taken into analysis. The illustration of data analysis and finding discussion was laid out along the training process: before and after the treatment.

\subsubsection{Before the Treatment}

The results of the pre-grammar paper test of the two groups, as shown in Table 4.1, indicated that though the experimental group got slightly higher scores than the control one $(\mathrm{M}=5.64 \mathrm{vs} . \mathrm{M}=5.43)$; there was no statistically significant difference between the two mean scores (sig. (2-tailed) $p=.451$ ). Also from the data in Table 2, the results of the pre-oral test of the two groups revealed that though the experimental group got slightly higher scores than the control one $(\mathrm{M}=5.77$ vs. $\mathrm{M}=5.68)$, no statistically significant difference was found between the two mean scores (sig. (2-tailed) $p=.591$ ). Thus, it was completely safe to confirm that the two groups were quite equivalent in both grammatical knowledge and oral performance before the treatment.

Table 2. Summary of pre-test results

\begin{tabular}{|c|c|c|c|c|c|c|c|c|c|}
\hline \multirow{2}{*}{ Group } & \multirow{2}{*}{$\mathrm{N}$} & \multicolumn{4}{|c|}{ Grammar-paper test } & \multicolumn{4}{|c|}{ Oral test } \\
\hline & & $\mathrm{M}$ & S.D. & $t$ & $p$ & $\mathrm{M}$ & S.D. & $t$ & $p$ \\
\hline Control & 37 & 5.43 & 1.24 & \multirow{2}{*}{-.76} & \multirow{2}{*}{.451} & 5.68 & 0.93 & \multirow{2}{*}{-.54} & \multirow{2}{*}{.591} \\
\hline Experimental & 37 & 5.64 & 1.20 & & & 5.77 & 1.00 & & \\
\hline
\end{tabular}

\subsubsection{After the Treatment}

\subsubsection{Grammar-Paper Tests}

From the data in Table 3, we can see that, on average, the two groups achieved strongly higher scores in the post-test than in the pre-test. Particularly, for the control group, the mean score of the post-test was 7.15 compared with 5.43 of the pre-test; and with the experimental group, the mean score of the post-test was 7.38 compared with 5.64 of the pre-test. Certainly, the variance was significantly different at the $p$-values of .00 levels for both groups; the null hypothesis could thus be rejected. This shows that teaching grammar with either GTM or CLT was effective in improving students' grammatical knowledge. A possible explanation for the above finding might be that in both methods of GTM and CLT, the target of form focus was met; though the meaning and use were primarily aimed at in the CLT class, the emphasis on form was not ignored during the training stages. Especially, that such mechanical drills as repetition, substitution, transformation, and question-answer were well designed and successfully deployed within the phase of controlled practice led to automatic and natural reflection of students, and provided students with intensive practice (Maley, 2011). This thereby guaranteed the enhancement in students' grammatical knowledge within both groups. That is, both GTM and CLT were effective in improving students' achievement of grammatical knowledge. 
Table 3. Summary of pre- and post-grammar paper test results

\begin{tabular}{|c|c|c|c|c|c|c|c|c|c|c|}
\hline \multirow{2}{*}{ Test } & \multicolumn{5}{|c|}{ Control group } & \multicolumn{5}{|c|}{ Experimental group } \\
\hline & $\mathrm{N}$ & $\mathrm{M}$ & S.D. & $t$ & $p$ & $\mathrm{~N}$ & $\mathrm{M}$ & S.D. & $t$ & $P$ \\
\hline Pre- & 37 & 5.43 & 1.24 & \multirow{2}{*}{-17.88} & \multirow{2}{*}{.00} & 37 & 5.64 & 1.20 & \multirow{2}{*}{-30.45} & \multirow{2}{*}{.00} \\
\hline Post- & 37 & 7.15 & 1.09 & & & 37 & 7.38 & 1.07 & & \\
\hline
\end{tabular}

Regardless of the fact that both methods of GTM and CLT improved students' achievement of grammatical knowledge after the treatment, that which method-CLT or GTM better improved students' achievement of this aspect needed an examination. In order to seek evidence for this investigation, an Independence-samples t-test was run to compare the mean scores between the two groups. The results can be summarized in Table 4 .

Table 4. Summary of post-grammar paper test results

\begin{tabular}{llllll}
\hline Group & $\mathrm{N}$ & $\mathrm{M}$ & $\mathrm{S} . \mathrm{D}$. & $t$ & $p$ \\
\hline Control & 37 & 7.15 & 1.09 & -917 & .36 \\
Experimental & 37 & 7.38 & 1.07 & & \\
\hline
\end{tabular}

It is apparent from Table 4 that, the experimental group got slightly higher scores than the control one $(\mathrm{M}=7.38$ vs. $\mathrm{M}=7.15$ ). However, the difference between the two mean scores was not statistically significant (sig. (2-tailed) $p=.36$ ). It was hence safe to accept the null hypothesis. This result strongly supported that the experimental group and the control one were equal in the outcome of grammatical knowledge. This finding may be explained by the fact that, in both methods of GTM and CLT, the target of form focus was equally paid attention to; all three dimensions of grammar instruction (form, meaning, and use) were well explained and practiced irrespective of their being taught inductively or deductively. Additionally, since both groups received the same great care from the teacher, they equally got high achievement in this aspect.

\subsubsection{Oral Tests}

As Table 5 shows, on average, the participants in the two groups achieved higher scores in the post-test than in the pre-test. Particularly, for the control group, the mean score of the post-test was 5.77 compared with 5.68 of the pre-test; and with the experimental group, the mean score of the post-test was 6.94 versus 5.78 of the pre-test. However, the difference between the pre- and the post-test within the control group was not significantly different $(p$-value $=.245)$; meanwhile, that of the experimental one showed a statistical significance ( $p$-value $=.00$ ). Therefore, the null hypothesis for the control group was accepted; whereas, that for the experimental one could be rejected. It is visible from the statistical difference that teaching grammar with GTM was ineffective in improving students' oral production; but CLT implementation brought great effect with respect to this aspect.

Table 5. Summary of pre- and post-oral test results

\begin{tabular}{lllllllllll}
\hline \multirow{2}{*}{ Test } & \multicolumn{3}{c}{ Control group } & \multicolumn{6}{c}{ Experimental group } \\
\cline { 2 - 11 } & $\mathrm{N}$ & $\mathrm{M}$ & S.D. & $t$ & $p$ & $\mathrm{~N}$ & $\mathrm{M}$ & S.D. & $t$ & $p$ \\
\hline Pre- & 37 & 5.68 & 0.93 & \multirow{2}{*}{-18} & \multirow{2}{*}{.245 } & 37 & 5.78 & 1.00 & \multirow{2}{*}{37.23} & .00 \\
Post- & 37 & 5.77 & 0.85 & & & 37 & 6.94 & 1.18 & & \\
\hline
\end{tabular}

Several possible explanations for this result may be laid out as the following. First, it was thanks to the dynamic conversations in the content and process of CLT class, which completely prevailed over GTM instruction that taught learners how to compose and comprehend sentences as isolated linguistic units of random utterance (Widdowson, 1978). Second, it was due to the more-explicit focus on communicative practice with the aim of training learners how to use sentences appropriately to achieve communicative purpose within CLT class (ibid.); meanwhile, such language activities as role-plays, problem-solving tasks, surveys, or information gaps were entirely strange to the control group. Third, during the training process, the students' language skills, especially their speaking skill were developed thanks to the proper integration of the grammar lessons with the four 
language skills. This is in agreement with Burns and Borg's (2005) findings, which showed the effectiveness of integration of the four language skills in promoting language learning. Last, the real-life situations set up within the stages of practice and production created an opportunity for students to communicatively use the target language and hone their negotiation skills as well (Thornbury, 1999).

In short, the present study found that the two methods of GTM and CLT were both effective in improving students' grammatical knowledge; and CLT was proved to be equal to GTM in this aspect. Furthermore, with respect to students' oral production, CLT created a great effect; whereas, GTM did not. These were owing to such factors as the sensible combination between the focus on form and the emphasis on meaning and use, the effective deploy of communicative tasks, the real-life situations set-up in the class, and the flexible integration of language skills within the CLT class.

\subsection{Research Question 2: What Are the Students' Attitudes towards the Communicative Grammar Teaching Method?}

To respond this research question, the type of descriptive statistics data from the questionnaire was analyzed. The results were also analyzed based on the advanced types of measurement: mean (M) and standard deviation (S.D.). For more convenience in discussing, the evaluation was rated based on a narrowed three-bank scale: low evaluation (1-2.8), medium evaluation (2.9-3.6), and high evaluation (3.7-5.0). The data analysis is going to be illustrated in both prose and tables, and organized along the three themes: lesson content, task design, and instruction effects.

\subsubsection{Theme 1: Lesson Content}

As shown in Table 6, most of the respondents recognized that the form of the new grammar points was well presented $(M=4.22)$ and well practiced $(M=4.10)$. The meaning and use of the new grammar points, according to their support, were also well presented $(M=4.30)$ and well practiced (4.10). With the four mean scores of $4.27,4.30,4.00$, and 3.97 corresponding to the integration of the grammar lessons with these skills of listening, speaking, reading, and writing, it is visible to learn that the majority of participants agreed that the grammar lessons were properly integrated with the four language skills. However, among these skills, speaking was showed to be most frequently integrated $(M=4.30)$; while writing was least constantly integrated $(M=3.97)$.

Table 6. Students' attitudes towards lesson content

\begin{tabular}{llll}
\hline Item & Content & M & S.D. \\
\hline 1 & Form of the new grammar points is well presented. & 4.22 & 0.53 \\
2 & Form of the new grammar points is well practiced. & 4.10 & 0.61 \\
3 & Meaning and use of the new grammar points are well presented. & 4.30 & 0.57 \\
4 & Meaning and use of the new grammar points are well practiced. & 4.10 & 0.66 \\
5 & The grammar lessons are properly integrated with these language skills: & & \\
& & 4.27 & 0.65 \\
a) Listening & 4.30 & 0.62 \\
b) Speaking & 4.00 & 0.58 \\
c) Reading & 3.97 & 0.80 \\
d) Writing & & \\
\hline
\end{tabular}

In short, these eight mean scores were all in the range of high evaluation (3.7-5.0); that is, the students' assessment of the lesson content was clearly positive. It seems possible that these results were due to several factors. First, the form of the target grammar points was paid enough attention to at the early stage of presentation via self-discovery of rules with the teacher's facilitation. It kept on being emphasized during the practice stage, especially within the sub-phase of controlled practice. Second, grammar, according to Brown (n.d.), gives the forms, but these forms are literally meaningless without meaning and use; therefore, in the domain of the treatment, the meaning and use were no less focused on from the start of the lessons. Via the contexts introduced in the presentation stage and the real situations set up within the stages of practice and production, the meaning and use were well practiced and consolidated, which reinforced the mastery of meaning and use of the grammar points. Last, during the training procedure, the grammar lessons were not taught in isolation but properly integrated with the four language skills as suggested in "Grammar Practice: Mechanical 
and Communicative" (n.d.). Particularly, from the start of each lesson, students were exposed to either spoken or written texts which gave them opportunities to practice listening or reading skill. Then, during the stage of practice, students had a lot of chances to practice two productive skills - speaking and writing.

\subsubsection{Theme 2: Task Design}

\subsubsection{In Presentation Stage}

As Table 7 reveals, the means ranging between 4.00 and 4.19 evidently offered positive results. A majority of the participants found the text topics introduced at the beginning of each lesson interesting $(M=4.19)$. They almost agreed that the follow-up tasks were designed at reasonable level for them to finish $(M=4.05)$. The teacher's directions actually facilitated them in discovering new grammar rules $(\mathrm{M}=4.11)$. This stage of presentation, according to their comments, did not take much time $(\mathrm{M}=4.16)$, however. Interestingly, in comparison between grammar-rule discovery and being directly provided by the teacher, the former was a preference to most of the participants $(M=4.00)$.

Table 7. Students' attitudes towards task design in presentation stage

\begin{tabular}{llll}
\hline Item & Content & M & S.D. \\
\hline 6 & The text topics used to introduce the new grammar points are interesting. & 4.19 & 0.52 \\
7 & The follow-up tasks are designed at reasonable level for me to deal with. & 4.05 & 0.70 \\
8 & The teacher's leading questions facilitate my self-discovery of grammar rules. & 4.11 & 0.57 \\
9 & $\begin{array}{l}\text { The phase of presenting the new grammar points is not time-consuming. } \\
\text { My self-discovery of the new grammar rules is better than being directly }\end{array}$ & 4.16 & 0.60 \\
& & 0.00 & 0.82 \\
\hline
\end{tabular}

Briefly, these five mean scores were all in the range of high evaluation (3.7-5.0); that is, the students' assessment of the task design in the presentation stage was obviously positive. These good results may be explained by these factors. First, the text topics and the follow-up tasks actually met the students' interest. All the texts exposed to students introduced such realistic and interesting topics as school life, home life, vacation, days off, parties, pastimes, sports, travelling, and tourism, etc. which were completely close to their daily life. The exposure of texts helped create natural language acquisition where grammar rules were absorbed subconsciously with little or no conscious focus (Brown, n.d.). Second, in working out the rules of the target structures embedded in the texts, the students were facilitated by the teacher's leading questions. It was this self-discovery of new knowledge that created the shift from the state of passiveness and boringness to activeness and criticalness within the participants. Last but not least, thanks to great efforts of both teacher and participants in the work of designing as well as executing the communicative activities, the stage of presentation was successfully accomplished within the planned time.

\subsubsection{In Practice and Production Stages}

The means ranging between 4.02 and 4.24, as can be seen in Table 8, obviously indicated positive responses from most of the participants to the six items related to this stage. Most of the respondents had strong agreement that the activities utilized in the practice and production stages were varied $(M=4.24)$. A majority of participants showed their approval to the view that the oral and written practices were well cooperated within the lesson procedure $(M=4.10)$. They mostly agreed that the activities in these stages were enjoyable $(M=4.16)$ and challenging enough for them to deal with $(\mathrm{M}=4.03)$. The two final mean scores $(\mathrm{M}=4.14$ and $\mathrm{M}=4.02)$ proved that the great benefits - accuracy and fluency these activities required and brought about were realized by most of the participants. That is, the different targets of each stage namely accuracy focus in the practice and fluency emphasis in the production were highly met. 
Table 8. Students' attitudes towards task design in practice and production stages

\begin{tabular}{llll}
\hline Item & Content & M & S.D. \\
\hline 11 & The activities applied to practice the new grammar points are varied. & 4.24 & 0.60 \\
12 & The forms of oral and written practices are well cooperated in this stage. & 4.10 & 0.70 \\
13 & The activities utilized to practice the new grammar points are enjoyable. & 4.16 & 0.65 \\
14 & The activities employed in this stage are challenging enough to perform. & 4.03 & 0.76 \\
15 & The first activities in this stage require me to get accuracy in grammar. & 4.14 & 0.67 \\
16 & The final activities in this stage require me to obtain fluency in communication. & 4.02 & 0.55 \\
\hline
\end{tabular}

In a nutshell, the six mean scores in the range of high evaluation (3.7-5.0) within this theme expressed a great concurrence of most of the respondents over the employed activities. These satisfying results may be explained by a number of different factors. First, the activities applied in the stage of practice were actually varied. They were successfully deployed in oral and written practices. Within the first sub-phase of practice namely guided or controlled practice, the students' involvement was maintained due to the easiness and quickness of mechanical drills. Also, this was owing to the practice in chorus which helped to bring about joyful learning atmosphere (Maley, 2011). In the next sub-phase of practice namely meaningful or less-controlled practice, students' motivation was boosted thanks to a variety of interesting and challenging tasks. Such meaningful tasks as role-plays, group discussions, surveys, information-gaps, personalization, and parallel writing did benefit students in getting chances to practice the target structures in meaningful contexts. This less-controlled sub-phase was actually a stepping-stone to prepare students for the communicative production (Ur, 1988).

Second, the shift from accuracy to fluency came into being at the end of the practice stage, and then fluency emphasis was intensified within the last stage of production. In this stage, the students had more chances to use the target language in real communicative situations. This stage reflected real language use outside the classroom and created an opportunity for students to hone their negotiation skills in the safety of the classroom (Thornbury, 1999). Students felt totally comfortable to be in company with their peers and were given more freedom to share their own ideas with friends. Basically, during this stage, students found it quite free to communicative with their mates within the domains of their interest without any interruption for error correcting from the teacher; their fluency was more enhanced thereby.

\subsubsection{Theme 3: The Instruction Effects}

As shown in Table 9, that all the seven mean scores were in the range of high evaluation (3.7-5.0) demonstrated the participants' positive attitudes towards the effects of the six instructed grammar lessons they had experienced. Commonly, the respondents found the training method really innovative $(M=3.97)$. Due to the innovativeness of the training method, their learning motivation was ignited $(\mathrm{M}=4.08)$. Besides, the participants became more critical in thinking and had to work actively due to the challenging tasks employed in the training process $(\mathrm{M}=$ 4.14). Experiencing the lessons, the participants found that working in pairs or groups helped decrease their stress and increase their confidence $(M=4.03)$. Significantly, they almost acknowledged that the learning collaboration was promoted due to pair-work and group-work $(\mathrm{M}=4.00)$. Finally, the majority of respondents supposed that they would be good at grammatical knowledge $(\mathrm{M}=3.94)$ and also able to communicate well in real-life situations thanks to the preeminence of the applied training method $(\mathrm{M}=4.05)$.

Table 9. Students' attitudes towards effects of instruction

\begin{tabular}{llll}
\hline Item & Content & M & S.D. \\
\hline 17 & The way of teaching grammar is innovative. & 3.97 & 0.79 \\
18 & The way of teaching grammar ignites my learning motivation. & 4.08 & 0.43 \\
19 & The way of teaching grammar requires me to think critically and work actively. & 4.14 & 0.42 \\
20 & Working in pairs and groups helps me feel less stressed and more confident. & 4.03 & 0.55 \\
21 & Pair-work and group-work encourage me to promote collaboration in learning. & 4.00 & 0.53 \\
22 & I suppose that these grammar lessons well prepare me for grammar-paper tests. & 3.94 & 0.62 \\
23 & I suppose that these grammar lessons well prepare me for real-life communications. & 4.05 & 0.74 \\
\hline
\end{tabular}


Broadly speaking, the grammar training conducted in a communicative way yielded nice effects on students' learning interest and was indeed favored by a majority of the participants. These detailed explanations may corroborate this expected result. First, the target grammatical items were naturally introduced via various vivid and realistic topics which were very close to the students' real-life situations (e.g. school life, home life, vacation, days off, parties, pastimes, sports, travelling, and tourism); they hence quickly caught the students' interest. This finding of the current study advocates the argument of Harmer (1998), who states that diversity and suitability of topics can be the "springboard" for fascinating lessons.

Second, the tasks for introducing, practicing, and consolidating the form, meaning and use of the target structures were well-designed and successfully carried out in various forms of oral and written practices and in accordance with the students' level-one of the factors of the appropriateness principle of grammar teaching introduced by Thornbury (1999). The encompassment of the three main dimensions of grammar instruction actually helped the participants obtain full understanding and ability to use the structure properly; both grammatical knowledge and oral communication were achieved thereby.

Third, tackling the communicative tasks, the participants became more active and critical in behaving and thinking due to the task requirement. Also, via dealing with tasks, the students had more chances to interact with their mates sharing their understandings as well as their own opinions. This finding of the current study obviously reinforces the relevant idea that CLT emphasizes on learning to communicate through interaction in the target language (Nunan, 1991).

Fourth, it was working in pairs and groups that helped decrease stress on students' learning and increase their interest and confidence in completing the tasks as well as using their own language to communicate regardless of strong or weak students. This consequently led to the fact that the students were no longer afraid of making mistakes, or even felt rude to question or argue with the teacher as used to be argued in Le-Canh (1999). In addition, within pairs or groups, students became comfortable with their peers in choosing to say, exchanging information, and receiving feedback from friends. The finding further supports the view of Richards (2006), who asserts that groups are real communities where learners learn through collaboration and sharing ideas.

Finally, it was due to the embrace of the three dimensions of grammar instruction as well as the integration of the language skills within the grammar training that a supposition of doing well conventional grammar-paper tests and performing properly in real-life communications were yielded within a majority of the participants. This finding of the current study seems to be consistent with the suggestion that grammar should not be treated separately from the language skills in the classroom (Nunan, 1991).

Shortly, it can be found from the present study that most of the participants supported the trial method with more positive than negative assessment of lesson content, task design, and effects of the instructed grammar lessons. As far as the lesson content and task design were concerned, they all highly met the students' satisfaction. Interestingly, the participants were involved in all the activities applied in the three stages of lesson procedure. A possible explanation for the results may be that such merits the innovation of grammar lessons instructed with CLT brought about as getting students' motivation-one of the keys to successful language learning and teaching (Oxford \& Shearin, 1994), creating activeness and criticality in behaviors and thinking, providing confidence and promoting learning collaboration caught the students' interest and met their satisfaction. They hence actually felt like learning with this method of training. In other words, the implementation of CLT in grammar training was actually effective in involving students' learning interest.

\section{Conclusions and Limitations}

\subsection{Conclusions}

The study was successful in seeking evidence for the effects of the application of communicative grammar teaching on (1) students' achievement of grammatical competence and oral performance and (2) students' attitudes towards the communicative grammar lessons. Specifically, the two major conclusions which could be drawn from the findings on the two research questions of the present study are going to be summarized as follows.

First, the finding on research question 1 "Does communicative grammar teaching affect students' achievement of grammatical knowledge and oral communication?" reveals that, being instructed grammar with CLT, the students achieved better outcomes not only in form but in function. This was evidently demonstrated by the results that the students who were taught grammar with CLT got higher scores both in grammar-paper test and oral test after the treatment than before ( $M=7.38$ vs. $M=5.64$ for grammar-paper test; $M=6.94$ vs. $M=5.78$ for oral test); and via t-test examinations, these differences were proved to be statistically significant ( $p$-value 
$=.00)$. Furthermore, the results on the oral post-test of the students who were taught grammar with CLT far outweighed those of the students who were taught grammar with GTM $(\mathrm{M}=6.94 \mathrm{vs} . \mathrm{M}=5.77)$; and through $\mathrm{t}$-test calculations, this statistic difference was proved to be highly significant $(p$-value $=.00)$.

Second, from the finding on research question 2 "What are students' attitudes towards communicative grammar teaching method?" we can see that, in addition to the students' improvement in both grammar competence and ability to use grammar communicatively, communicative grammar lessons did get positive attitude from the students. This is confirmed by the finding derived from the student questionnaire. All the mean scores were in the range of high evaluation (3.7-5.0). This finding asserts that beside the effect that communicative grammar teaching brings about in terms of developing the students' grammar competence and oral performance, it actually catches the students' learning interest. This enhances the constructive view on communicative grammar teaching within the teachers of English in Le Hong Phong Junior High School and fosters them thoroughly apply it to boost their professional competence.

Shortly, the current finding shows that communicative grammar teaching did benefit the students both in grammatical competence and oral performance; it did appeal the students' interest in grammar lessons, also. It hence richly deserves application in teaching grammar within the context of Le Hong Phong Junior High School.

\subsection{Limitations}

Though the study got certain success, several limitations due to practical constraints need to be acknowledged. First, the number of the target grammar points taken into the treatment was rather limited (six points). It would have provided more convincing results if it had included all the curricular grammar points of the first semester. Second, the tests, both the pre- and the post-tests, did not cover all the four language skills, so the collected data could not comprehensively indicate the students' communicative performance. Besides, the grammar-paper tests were developed with a relatively modest number of items (twenty-five items), which might more or less affect the reliability of the current study. Third, due to the fact that both the questionnaire and the pre- and the post-tests were developed by the researcher, a little limitation might arise in validating the research instruments. Finally, it was beyond the scope of this study to examine the topic through all the students of four grades, so just $7^{\text {th }}$ graders were involved. Additionally, the study was conducted in a small scale of subjects - Le Hong Phong Junior High School, which is a fairly prestige school in the city; hence, the findings are not intended to be generalized to other schools.

\section{References}

Bachman, L. F., \& Palmer, A. S. (1996). Language Testing in Practice: Design and Developing Useful Language Tests. Oxford: Oxford University Press.

Brown, H. D. (n.d.). Principles of Language Learning and Teaching (3rd ed., pp. 244-245). California: Prentice-Hall Regents.

Burns, A., \& Borg, M. (2005). Grammar and Communicative Language Teaching: Why, When and How to Teach It? Applied Linguistics and Language in Education Research Centre. Phnom Penh: Camtesol Conference (February, 2009).

Grammar Practice: Mechanical and Communicative. (n.d.). Retrieved August 25, 2011, from http://www.teachertraining.hu

Harmer, J. (1998). How to Teach English (pp. 4-5). Retrieved August 15, 2010, from http://www.languages.ait.ac.th/hanoi_proceedings/canh.html

Harmer, J. (1998). How to Teach English: An Introduction to the Practice of English Language Teaching. Addison: Longman Ltd.

Heaton, J. B. (1989). Writing English Language Tests (2nd ed.). New York: London and New York.

Khuong-Cam, T. H. (2010). Teaching Communicative English Grammar to Vietnamese High School Students in Vung Tau City. Ho Chi Minh City: HOU.

Le-Canh, V. (1999). Language and Vietnamese Pedagogical Contexts. Retrieved October 24, 2011, from htpp://www.languages.ait.ac.th/Hanoi_proceedings/canh.htm

Maley, A. (2011). Advanced Methodology: Provisional Course Outline (Unpublished).

Murcia, C., \& Hilles, S. (1988). Techniques and Resources in Teaching Grammar. New York: Oxford University Press.

Nguyen-Giao, Q., \& Nguyen-Hoa, T. N. (2004). Applying Communicative Methods to Teaching Grammar: An 
Experiment (pp. 16-25). Teacher's Edition.

Nunan, D. (1991). Language Teaching Methodology: A Textbook for Teachers. London: Prentice Hall International.

Oxford, R. L., \& Shearin, J. (1994). Language Learning Motivation: Expanding the Theoretical Framework. The Modern Language Journal, 78, 12-28. Oxford: Oxford University Press.

Richards, J. C. (2006). Communicative Language Teaching Today. London: Cambridge University Press.

Singh, R. (2011). Controversies in Teaching English Grammar. Academic Voices: A Multidisciplinary Journal, $1(1), 56-60$.

Thornbury, S. (1999). How to Teach Grammar. In J. Harmer (Ed.), How to Teach English. London: Pearson Education Ltd.

Ur, P. (1988). Grammar Practice Activities: A Practical Guide for Teachers. Cambridge: Cambridge University Press.

Widdowson, H. G. (1978). Teaching Language as Communication. London: Oxford University Press.

\section{Copyrights}

Copyright for this article is retained by the author(s), with first publication rights granted to the journal.

This is an open-access article distributed under the terms and conditions of the Creative Commons Attribution license (http://creativecommons.org/licenses/by/3.0/). 